\title{
10 health stories that mattered: June 19-25
}

- Vancouver became the first Canadian city to regulate medical marijuana dispensaries, despite a warning against doing so from federal Health Minister Rona Ambrose. Dispensaries have to pay a $\$ 30000$ licensing fee (\$1000 for compassion clubs) and must be located at least 300 metres from schools, community centres and other dispensaries.

- The clinical trial of an experimental Canadian Ebola drug has ended because "continuing enrollment was not likely to demonstrate an overall therapeutic benefit." The drug, TKMEbola-Guinea, made by Tekmira Pharmaceuticals, was being evaluated in patients with Ebola in Sierra Leone.

- Smoking, binge drinking and obesity are major problems in Canada's three territories. According to recently released data from Statistics Canada, the Northwest Territories has Canada's highest rates of obesity $(33.7 \%)$ and heavy drinking (32.7\%), Nunavut has the highest smoking rate $(62 \%)$ and Yukon has the secondhighest rate of heavy drinking $(27.8 \%)$ and the third-highest smoking rate $(26.2 \%)$.

- McGill University's medical school in Montréal was put on probation by Canadian and US accrediting bodies for inadequacies in 24 areas and has two years to "demonstrate significant progress" in addressing the problems. Shortcomings listed by investigators include administrative matters, inconsistent educational experiences and inadequate instruction on women's health.

- Health Canada announced that plainlanguage labelling regulations for prescription drugs come into force this month. "Drug labels that are easy to read and understand help Canadians to use the right medications correctly and avoid potentially dangerous medication errors," stated a press release.

- The Canadian Cancer Society is calling on the federal government to show more leadership in fighting cancer or "there is a risk that the rising number of cancer cases will overwhelm our health care system." Recommendations made by the society include reducing smoking by adopting plain packaging for cigarettes, improving access to palliative care and committing to long-term investments in cancer research.

- Seven health researchers fired by the government of British Columbia, and the sister of an eighth researcher who committed suicide after being fired, are calling for a public inquiry into their termination. The research- ers were fired in 2012 over an alleged breach of confidential data, and repeated calls for an inquiry into the incident have been rejected by the government.

- Rural general practitioner Dr. Alan Ruddiman won the run-off vote to lead Doctors of $\mathrm{BC}$, defeating Dr. Brian Day, an outspoken advocate for increasing access to private health care services. Day had earlier been declared the winner by one vote, but a recount found the doctors had tied, forcing a run-off election.

- The number of regulated nurses in Canada declined in 2014 for the first time in 20 years, according to a report from the Canadian Institute for Health Information. The slow growth in the number of licensed practical nurses $(1.4 \%)$ and registered psychiatric nurses $(1.3 \%)$ was offset by a $1 \%$ decline of registered nurses.

- Two of Canada's largest medical marijuana companies have merged and will now serve $25 \%$ of all registered patients in the country. Tweed Marijuana Inc. will be joining Bedrocan Cannabis Corp., the first merger in the fledgling medical marijuana industry. — Roger Collier, CMAJ

CMAJ 2015. DOI:10.1503/cmaj.109-5110 